\title{
EL ALCANCE DE LOS PRINCIPIOS GENERALES DEL ESTATUTO DEL CONSUMIDOR COLOMBIANO*
}

\section{THE SCOPE OF THE GENERAL PRINCIPLES OF CONSUMER LAW IN COLOMBIA}

\author{
Fernando Andrés Pico-Zúniga*** \\ Fecha de recepción: 2 de septiembre de 2016 \\ Fecha de aceptación: 3 de febrero de 2017 \\ Disponible en línea: 30 de mayo de 2017
}

\section{Para citar este artículo/To cite this article}

Pico-Zúñiga, Fernando Andrés, El alcance de los principios generales del Estatuto del Consumidor colombiano, 134 Vniversitas, 291-326 (2017). http://dx.doi.org/10.11144/Javeriana.vj134.apge

doi:10.11144/Javeriana.vj134.apge

* Artículo investigativo producto de la línea de pesquisa acerca de las relaciones de consumo en el Derecho colombiano del Grupo de Investigación en Derecho Privado de la Facultad de Ciencias Jurídicas, Pontificia Universidad Javeriana.

** Abogado y profesor titular de las cátedras de títulos valores y protección al consumidor de la Facultad de Ciencias Jurídicas, Pontificia Universidad Javeriana, orcid.org/0000-0003-4682-522X. Magíster en derecho de la empresa y de los negocios, Universidad de Barcelona. Miembro del Grupo de Investigación en Derecho Privado de la Facultad de Ciencias Jurídicas, Pontificia Universidad Javeriana. Asesor jurídico de la Presidencia de la Federación Nacional de Comerciantes, FENALCO, Bogotá. Contacto: fernandopicozuniga@gmail.com, fpico@javeriana.edu.co 


\section{RESUMEN}

El Estatuto del Consumidor colombiano —-Ley 1480 de 2011 - plantea todavía grandes retos e inquietudes conceptuales y prácticas, frente a las cuales autores y jurisprudencia deben ofrecer soluciones que permitan una mejor comprensión del sistema. En ese contexto, y como elemento esencial para ese fin, es fundamental analizar el alcance y significado que tienen los principios del Estatuto del Consumidor que operan como herramientas ilustradoras, interpretativas e integradoras del ordenamiento de consumo. Así, el presente documento se propone estudiar la extensión y las implicaciones de los principios establecidos en el artículo 1 de la Ley 1480 de 2011, para concluir que, además de compartir la funcionalidad común que le han sido atribuidas a todos los principios de Derecho, los principios de protección al usuario se instituyen como una de las piedras angulares de lo que se viene reconociendo como Derecho del Consumo en Colombia.

Palabras clave: Principios generales de Derecho; Estatuto del Consumidor (Ley 1480 de 2011); principios generales del Estatuto del Consumidor; Derecho del Consumo 


\section{ABSTRACT}

The Colombian Consumer Act — Law 1480, 2011 — still generates relevant questions about how to explain the protection system of users. That said, it is important to study the meaning and effect of the principles of the Colombian Consumer Act - article 1-, that involve the essential and basic issues of Consumer Law in this country. With this goal in mind, this paper aims to examine the implications of those principles in order to think about a Consumer Law in Colombia that suggest an organized and harmonic system of rules aiming for the protection of the consumers. This is because the mentioned principles and the Colombian Consumer Act are the mainstay of this new part of law.

Keywords: general principles of law; consumer act (Law 1480, 2011); general principles of consumer act; consumer law

\section{SUMARIO}

INTRODUCCIÓN.- I. LOS PRINCIPIOS GENERALES DEL ESTATUTO DEL CONSUMIDOR Colombiano.- A. El ámbito de aplicación de los principios del Estatuto del Consumidor colombiano.- B. La extensión de los principios del Estatuto del Consumidor colombiano.- II. LOS PRINCIPIOS GENERALES DEL ARTíCUlO 1 del Estatuto del Consumidor colombiano.- A. El libre ejercicio de los derechos de los consumidores.- $B$. El respeto a la dignidad y los intereses económicos de los usuarios.- $C$. La protección de los consumidores frente a los riesgos para su salud y seguridad.- D. El acceso de los consumidores a una información adecuada, de acuerdo con los términos de esta ley, que les permita hacer elecciones bien fundadas.- E. La educación del consumidor.- F. La libertad de constituir organizaciones de consumidores y la oportunidad para esas organizaciones de hacer oir sus opiniones.- G. La protección especial a los niños, niñas y adolescentes, en su calidad de consumidores, de acuerdo con lo establecido en el Código de la Infancia y la Adolescencia.- Conclusiones.- Bibliografía. 


\section{INTRODUCCIÓN}

El Estatuto del Consumidor colombiano - Ley 1480 de 2011- (en adelante, EC o Estatuto) ${ }^{1}$ plantea todavía grandes inquietudes y retos teóricos y prácticos.

En efecto, aunque el $\mathrm{EC}$ ha constituido un hito legal en nuestro país, en la medida en que ha puesto a tono el ordenamiento jurídico nacional frente a las necesidades económicas, sociales y normativas patrias y extranjeras en materia de protección al consumidor, sigue ofreciendo interrogantes fundamentales que van desde la existencia y naturaleza de un Derecho del Consumo en Colombia, con las implicaciones que ello acarrea, pasando por el entendimiento y la aplicación de regímenes como el de la responsabilidad por productos defectuosos o la reversión de pagos, hasta la proyección de las facultades sancionatorias y jurisdiccionales de la Superintendencia de Industria y Comercio, tanto para usuarios como para productores y proveedores.

En este contexto, sobresalen también preguntas estructurales sobre los principios generales del EC, que llevan a proponer la visión global y fundante de todo el ordenamiento de la protección al usuario en nuestro país. Temas como el ámbito de aplicación de los principios, su extensión o agotamiento en el artículo 1 del EC y el alcance y proyección de cada uno de ellos, son asuntos cardinales que buscan darles sentido a las normas referentes a la salvaguardia de los intereses de los consumidores, integrarlas en hipótesis oscuras y consolidarlas como un verdadero Derecho del Consumo.

Precisamente, y aunque la cuestión requiere un análisis mucho más profundo y posterior, si el Derecho se concibe como un conjunto de normas y principios armónicamente dispuestos que rigen la vida de los seres humanos, podría sostenerse con claridad meridiana que las reglas del EC son las disposiciones fundantes de la protección de los consumidores y los principios del mismo los lineamientos en el plano del ser y el deber ser que guían la creación, interpretación y consolidación del llamado Derecho del Consumo en Colombia.

1 Colombia, Ley 1480 de 2011, por medio de la cual se expide el Estatuto del Consumidor [EC] y se dictan otras disposiciones, 48.220 Diario Oficial, 12 de octubre de 2011. Disponible en: http://www. secretariasenado.gov.co/senado/basedoc/ley_1480_2011.html 
En lo que se refiere al estudio de ambas fuentes normativas —normas y principios_-, la jurisprudencia y la academia juegan un papel principal para analizar y llenar de contenido las reglas dispuestas en el EC y su significado en el ordenamiento. Por esa razón, desde el segundo campo pero amparado en el primero, el presente documento, como producto de la línea de investigación en materia de Derecho del Consumo del Grupo de Investigación en Derecho Privado de la Pontificia Universidad Javeriana, busca examinar y comprender la trascendencia jurídica de los principios generales que gobiernan el EC.

Para ello, el estudio parte de la función tripartita de los principios generales del Derecho, atribuibles también a los principios que mandan al EC, con el propósito de, primero, estudiar la categoría de los principios de la Ley 1480 de 2011 y, en consecuencia, indagar sobre su alcance y extensión; segundo, examinar uno a uno los principios determinados en el artículo 1 del Estatuto, y; por último, en tercer lugar, ofrecer algunas conclusiones.

\section{LOS PRINCIPIOS GENERALES DEL ESTATUTO DEL CONSUMIDOR COLOMBIANO}

El artículo 1 del Estatuto del Consumidor colombiano dispone:

"Esta ley tiene como objetivos proteger, promover y garantizar la efectividad y el libre ejercicio de los derechos de los consumidores, así como amparar el respeto a su dignidad y a sus intereses económicos, en especial, lo referente a: 1 . La protección de los consumidores frente a los riesgos para su salud y seguridad. 2. El acceso de los consumidores a una información adecuada, de acuerdo con los términos de esta ley, que les permita hacer elecciones bien fundadas. 3. La educación del consumidor. 4. La libertad de constituir organizaciones de consumidores y la oportunidad para esas organizaciones de hacer oír sus opiniones en los procesos de adopción de decisiones que las afecten. 5. La protección especial a los niños, niñas y adolescentes, en su calidad de consumidores, de acuerdo con lo establecido en el Código de la Infancia y la Adolescencia”.

De este modo, el artículo 1 del EC consagra los principios del Derecho del Consumo que corresponden a las normas jurídicas con supuestos genéricos, inspiradoras de otras reglas dentro del 
ordenamiento del consumo, aplicables ante los vacíos normativos de la protección al consumidor y que actúan como herramienta interpretativa frente a las demás normas jurídicas referentes a la salvaguardia de los derechos de los usuarios.

Así, los principios generales del EC, aunque establecen particularidades que le son propias, las cuales se analizarán con posterioridad, no distan sustancialmente del alcance y entendimiento que se tiene sobre los principios del Derecho.

Por ese motivo, vale resaltar que los principios del EC fungen como pautas para la creación e información de las disposiciones protectoras de los usuarios, operan como normas integradoras y totalizadoras de los vacíos del ordenamiento del consumidor y pueden ser empleadas como herramientas de interpretación o aclaración frente a aquellas disposiciones jurídicas, actos u omisiones de los actores de consumo que se muestran oscuras o contradictorias a la luz de la normativa.

Sin perjuicio de ello, sobre el artículo 1 citado sobresalen a esta altura dos preguntas fundamentales, previas al análisis que se propone: primero, ¿cuál es el ámbito de aplicación de los principios del estatuto del consumidor?, y segundo, ¿los principios del Estatuto del Consumidor se agotan en la lista que ofrece el artículo 1 de ese cuerpo normativo?

\section{A. El ámbito de aplicación de los principios del Estatuto del Consumidor colombiano}

Cuando se alude al campo de aplicación de los principios generales del EC debe indudablemente acudirse al ámbito de destino de todas las reglas contenidas en ese cuerpo normativo. Al respecto, el artículo 2 del Estatuto, referente a su objeto, indica que "Las normas de esta ley regulan los derechos y las obligaciones surgidas entre los productores, proveedores y consumidores y la responsabilidad de los productores y proveedores tanto sustancial como procesalmente [...]".

La referida disposición ha sido criticada por algunos autores en atención a su amplitud y falta de claridad ${ }^{2}$. Sin embargo, y al igual

2 Javier Tamayo-Jaramillo, al estudiar el asunto, indica que "el artículo 2 del Estatuto (...) es una norma demasiado abierta que da lugar a dos interpretaciones posibles: o bien, uno entiende que el 
que lo considerado por el profesor Tamayo-Jaramillo, pensamos que tras una lectura sistemática de las disposiciones normativas del EC - artículos 3 y 5 en particular - el ámbito de aplicación de la Ley 1480 de 2011 se circunscribe a las figuras e instituciones de protección al consumidor reguladas expresamente en él. De manera que las obligaciones y los contratos reglados en el Código Civil y el Código de Comercio siguen vigentes, salvo en lo que ha sido ordenado en el EC para la protección de los derechos de los usuarios — garantía, retracto, cláusulas abusivas, condiciones generales de contratación, entre otros- 3 .

De este modo, los principios generales de que trata el artículo 1 del EC rigen y se extienden a todas y cada una de las reglas establecidas en ese cuerpo normativo.

Ahora, ¿qué acontece frente a las normas especiales de protección al consumidor?, ¿los principios generales del artículo 1 del Estatuto se extienden a esas normativas particulares?

Al respecto, el ya citado artículo 2 de EC establece que "Las normas contenidas en esta ley son aplicables en general a las relaciones de consumo y a la responsabilidad de los productores y proveedores frente al consumidor en todos los sectores de la economía respecto de los cuales no exista regulación especial, evento en el cual aplicará la regulación especial y suplementariamente las normas establecidas en esta Ley". Aunque es evidente que el EC es norma residual en materia de protección al usuario, las disposiciones de la Ley 1480 de 2011 no son claras en establecer qué tipo de vínculo tiene el EC, norma general en materia de consumo, frente a aquellas leyes o normas especiales en ese campo.

Estatuto regula la totalidad de los derechos y obligaciones de los contratos civiles y mercantiles, en los que haya una relación de consumo, y que cualquier desacuerdo contractual relacionado con esos derechos y obligaciones, le otorga competencia a la Superintendencia de Industria y Comercio para conocer de dicho conflicto, en cuyo caso los Códigos de Comercio y Civil quedarían absorbidos por el Estatuto en lo relacionado con todas las obligaciones y derechos de esos contratos celebrados con el consumidor. O bien, se entiende que el objeto y el campo de aplicación de la Ley 1480 se refieren únicamente a las instituciones protectoras del consumidor establecidas dentro del mismo Estatuto y otras normas especiales de la misma naturaleza, en cuyo caso, lo no regulado expresamente por el Estatuto queda por fuera de la jurisdicción y competencia de la Superintendencia de Industria y Comercio". JaVier TAMAYO-JARAMILlo, Responsabilidad por productos defectuosos, 29 (Editorial Legis, Bogotá, 2016).

3 JaVier TAmayo-JARAmillo, Responsabilidad por productos defectuosos, 29 (Editorial Legis, Bogotá, 2016). 
La cuestión es fundamental no solo para responder en concreto a los interrogantes sobre la extensión de los principios generales de la Ley 1480 a las normas especiales de protección al usuario, sino adicionalmente para esclarecer si es dable referirse al Derecho del Consumo como un conjunto sistemático de reglas dirigidas a la salvaguardia de los derechos de los consumidores, o más bien comprender las reglas en protección al usuario como un conjunto de disposiciones atomizadas con una vinculación meramente accesoria.

Para clarificar el punto, debe acudirse entonces a fuentes externas a la norma. Primero, las disposiciones que el legislador colombiano pretende incorporar al EC; segundo, la exposición de motivos del EC y, tercero, el entendimiento jurisprudencial sobre el Derecho de Consumo en nuestro país.

En ese orden de ideas, el recientemente conocido proyecto de ley $37 / 2014 \mathrm{C}, 74 / 2015 \mathrm{~S}^{4}$, pretendía incorporar en el EC el retracto aeronáutico, que en su momento se introdujo mediante la Resolución 1375 de 2015 de la Aeronáutica Civil ${ }^{5}$. En efecto, antes de la aparición del proyecto de ley antedicho, que por demás llegó a sanción presidencial, se planteó la inquietud relativa a si una regla de rango normativo inferior y posterior al EC - Resolución 1375 de 2015 de la Aerocivil—, por muy especial que fuera, podía contrariar las disposiciones de la Ley 1480 de 2011, en particular en materia de retracto. En ese contexto, el proyecto de ley 37/2014C, 74/2015S, buscó fulminar todo tipo de duda en torno a la relación entre las normas especiales de consumo versus el EC.

El artículo 8 del proyecto de ley enunciado dispuso: "En caso de conflicto o duda sobre la aplicación entre estas normas y los Reglamentos Aeronáuticos de Colombia, prevalece la más favorable al usuario. La norma que se adopte debe aplicarse en su integridad".

4 Colombia, Proyecto de Ley 37/2014 Cámara, 74/2015 Senado, por medio de la cual se agrega un artículo a la Ley 1480 de 2011, con el fin de proteger al consumidor del servicio de transporte aéreo nacional de pasajeros, 827 Gaceta del Congreso, 9 de diciembre de 2014. Disponible en: http:// servoaspr.imprenta.gov.co/gacetap/gaceta.nivel_3

5 Colombia, Aeronáutica Civil, Resolución 1375 de 2015, por la cual se modifican unos numerales del RAC 3 de los Reglamentos Aeronáuticos de Colombia, 49.541 Diario Oficial, 12 de junio de 2015. Disponible en: http://www.imprenta.gov.co/diariop/diario2.nivel_3, http://www.avianca.com/es/ Documents/resolucion-de-retracto-y-desistimiento.PDF

6 Colombia, informe de conciliación al Proyecto de Ley 74 de 2015 Senado, 37 de 2014 Cámara, por medio de la cual se establecen mecanismos de protección al usuario del servicio de transporte aéreo nacional de pasajeros y se dictan otras disposiciones, 434 Gaceta del Congreso, 16 de junio de 2016. 
De ahí que entre las normas especiales y las genéricas de consumo haya un vínculo jerárquico de favorabilidad en amparo del usuario, que a nuestro entender también se desdobla a todas las normas específicas de protección a los consumidores.

Esta tesis es corroborada por la exposición de motivos del EC y la jurisprudencia de la Corte Constitucional que se ha ocupado del tema. En efecto, de acuerdo con la exposición de motivos de la Ley 1480 de 2011: "El estatuto de defensa del consumidor ha sido concebido como una normatividad en la cual se consagran los principios generales aplicables a todos los actores que interactúan en el mercado del consumo. Lo que se persigue con la expedición de este proyecto de ley, es la creación de un solo sistema de protección al consumidor que cobije todos los ámbitos del quehacer económico. Se ha considerado que no deben existir reglas distintas para cada ámbito o sector ya que ello, además de generar confusión entre las autoridades encargadas de velar por el cumplimiento de las normas, va en detrimento del consumidor quien debe enfrentarse a normatividades y entidades diferentes. Conscientes de las diferencias existentes entre las relaciones de todos los actores del consumo de cada sector, la actualización contempla la posibilidad de expedir reglas específicas que regulen las particularidades de cada ámbito”. De modo que aunque es admisible la promulgación de normas especiales en materia de consumo, ellas deben estar armónicamente sistematizadas y comprendidas junto al EC, que se establece como pilar del sistema de protección al consumidor colombiano.

Y no puede ser de otra manera. Ordenar el Derecho de retracto aeronáutico, o hipotéticamente la reversión de pago en el ámbito automotor, entre otros, es extender los efectos de los conceptos y disposiciones del EC a otros sectores de la economía, porque de lo contrario sería imperiosa la aplicación de las disposiciones del Estatuto. De ahí que no podría hablarse ni siquiera de retracto aeronáutico, o de cualquier derecho de consumo en alguna fracción de mercado especial, si el propio Estatuto no hubiere introducido la materia en nuestro ordenamiento.

Disponible en: http://www.imprenta.gov.co/gacetap/gaceta.mostrar_documento?p_tipo=123\&p_ numero $=74 \& p \_$consec $=44926$ 
En igual sentido lo ha comprendido la Corte Constitucional colombiana que, mediante la sentencia C-896-127, al estudiar la constitucionalidad del artículo 80 del EC y trayendo a colación su exposición de motivos, indicó que "La ley 1480 de 2011 tiene un contenido temático inequívoco: la adopción de un régimen de protección al consumidor. Ello resulta claro (i) del título de la ley en el que se anuncia que 'Se expide el Estatuto del Consumidor y se dictan otras disposiciones'; (ii) de los principios generales definidos en el artículo $1^{\circ}$, en los que se destaca como objetivo de ley, la protección, promoción y garantía de la efectividad y libre ejercicio de los derechos de los consumidores [...]".

De manera que la Ley 1480 de 2011 se erige en nuestro ordenamiento como la norma de normas en materia de protección al consumidor, permea las disposiciones especiales de consumo y se extiende a todas ellas.

Por esas razones, los principios generales consignados en el artículo 1 del EC alcanzan también las disposiciones que regulan la protección de los usuarios en sectores especiales. Eso sí, junto a aquellos principios que, de forma respectiva, puedan también mandar la salvaguardia de las garantías de los consumidores en ese sector económico concreto que ordenan.

\section{B. La extensión de los principios del Estatuto del Consumidor colombiano}

La segunda cuestión a resolver es si los principios generales del EC se agotan en lo consignado por el artículo 1 de ese cuerpo normativo. Sobre ello debe señalarse de entrada que no. Los principios generales que mandan la protección de los intereses de los consumidores no se extinguen en las disposiciones consagradas por el artículo 1 en mención.

En esencia porque hay principios de Derecho que imperan en todo el ordenamiento jurídico, también aplicables al EC, y porque adicionalmente, en virtud de lo dispuesto por el inciso 4 del artículo 4 del EC, aquello que no pueda ser resuelto por las reglas y princi-

7 Colombia, Corte Constitucional, Sentencia C-896-12, 31 de octubre de 2012, magistrado ponente Mauricio González-Cuervo. Disponible en: http://www.corteconstitucional.gov.co/ RELATORIA/2012/C-896-12.htm 
pios sustanciales del EC, se regirá por las disposiciones del Código de Comercio y el Código Civil, siempre que no contravengan los principios de la Ley 1480 de $2011^{8}$. Por esto, los principios de esas codificaciones también podrían ser aplicables al EC 9 .

Ejemplo de ello es la proyección del principio de la buena fe en el Estatuto. Aunque el EC solo consagra el deber de actuar de buena fe sobre el consumidor —artículo $3{ }^{10}{ }^{10}$, autores especializados y la jurisprudencia de la Sala de Casación Civil de la Corte Suprema de Justicia y la Corte Constitucional han reconocido la trascendencia del principio de la buena fe en todos los campos del Derecho y, en particular, en el ámbito del EC.

En efecto, Gustavo Ordoqui concluye con notada certeza, al analizar los alcances de la buena fe en todo el Estatuto, que "La ley 1480 referente al Estatuto del Consumidor en esencia responde a las exigencias del artículo 83 de la Constitución de la República y supone una progresiva revalorización de la buena fe de base constitucional que exige una nueva dimensión ética de la autonomía privada en las relaciones en las que se encuentran un fuerte con un débil. En las relaciones de consumo no rige solo el principio de la autonomía privada sino que coexiste con el principio de la buena fe y en ello se encuentra el verdadero fundamento de las relaciones de consumo obligacionales con carácter general velándose por la

8 "Artículo 4. Carácter de las normas. (...) En lo no regulado por esta ley, en tanto no contravengan los principios de la misma, de ser asuntos de carácter sustancial se le aplicarán las reglas contenidas en el Código de Comercio y en lo no previsto en este, las del Código Civil. En materia procesal, en lo no previsto en esta ley para las actuaciones administrativas se le aplicarán las reglas contenidas en el Código Contencioso Administrativo y para las actuaciones jurisdiccionales se le aplicarán las reglas contenidas en el Código de Procedimiento Civil, en particular las del proceso verbal sumario".

9 Lo propio para los principios procesales consagrados en el Código Contencioso Administrativo y el hoy Código General del Proceso, los cuales también serían extensibles al EC.

10 "Artículo 3. Derechos y deberes de los consumidores y usuarios. Se tendrán como derechos y deberes generales de los consumidores y usuarios, sin perjuicio de los que les reconozcan leyes especiales, los siguientes: (...) 2. Deberes. (...) 2.2. Obrar de buena fe frente a los productores y proveedores y frente a las autoridades públicas".

"Estando a una primera lectura meramente formal del articulado comenzamos por señalar que a primera vista puede parecernos un tanto pobres las referencias que se realizan expresamente a la buena fe en dicho texto normativo. Llama la atención incluso que, en concreto, a la buena fe se realiza referencia expresa no tanto al referir a las obligaciones de los proveedores sino al aludir a la conducta debida del consumidor cuando en el artículo 3.2.2 de la referida ley se expresa como deber del consumidor: 'Obrar de buena fe frente a los productores y proveedores y frente a las autoridades públicas" (cursiva propia). GuSTAVo Ordoqui-CASTILla, Buena fe contractual, 637 (Editorial Pontificia Universidad Javeriana, Grupo Editorial Ibáñez, Universidad Católica de Uruguay, Bogotá, 2012). 
real protección de ese no solo por lo que tiene sino en cuanto es como persona"l1.

Adicionalmente, la Sala de Casación Civil de la Corte Suprema ha indicado con respecto a la buena fe "[...] principio vertebral de la convivencia social, como de cualquier sistema jurídico, en general, lo constituye la buena fe, con sujeción a la cual deben actuar las personas — sin distingo alguno- en el ámbito de las relaciones jurídicas e interpersonales en las que participan, bien a través del cumplimiento de deberes de índole positiva que se traducen en una determinada actuación, bien mediante la observancia de una conducta de carácter negativo (típica abstención), entre otras formas de manifestación. Este adamantino axioma, insuflado al ordenamiento jurídico — constitucional y legal-y, en concreto, engastado en un apreciable número de instituciones, grosso modo, presupone que se actúe con honradez, probidad, honorabilidad, transparencia, diligencia, responsabilidad y sin dobleces. Identifícase entonces, en sentido muy lato, la bona fides con la confianza, la legítima creencia, la honestidad, la lealtad, la corrección y, especialmente, en las esferas prenegocial y negocial, con el vocablo 'fe', puesto que 'fidelidad, quiere decir que una de las partes se entrega confiadamente a la conducta leal de la otra en el cumplimiento de sus obligaciones, fiando que esta no lo engañará"'12. Por esto, en el marco de cualquier relación jurídica, que también las tratativas, entre las que se ubican sin lugar a dudas las relaciones de consumo, las partes deben seguir los postulados de la buena fe que exigen una conducta honesta, proba y sin dobleces frente al cocontratante.

Más todavía, en el campo particularmente contractual del EC, la buena fe tiene una significativa manifestación, aunque no esté expresamente consagrada. No debe olvidarse, que por virtud del inciso 4 del artículo 4 del EC, a lo no regulado de forma sustancial por la Ley 1480, mientras no contravengan los principios de esa normativa, le serán aplicables las reglas contenidas en el Código de Comercio y, en lo no previsto en este, las del Código Civil. De ahí que los artículos 863 y 871 del Código de Comercio, referentes a la

11 Gustavo Ordoqui-Castilla, Buena fe contractual, 643-644 (Editorial Pontificia Universidad Javeriana, Grupo Editorial Ibáñez, Universidad Católica de Uruguay, Bogotá, 2012).

12 Colombia, Corte Suprema de Justicia, Sala de Casación Civil, Expediente 6146, 2 de agosto de 2001, magistrado ponente Carlos Ignacio Jaramillo-Jaramillo. Disponible en: http://consultajurisprudencial. ramajudicial.gov.co/WebRelatoria/csj/index.xhtml 
buena fe en la etapa precontractual y en la celebración y cumplimiento de los contratos, tengan plena aplicación en el EC. No solo porque nada indica el Estatuto sobre la buena fe en los contratos de consumo, por lo cual se adaptarían subsidiariamente las reglas señaladas del Código mercantil, sino porque, se itera, el principio de la buena fe permea todas las relaciones negociales en razón a lo reglado en el artículo 86 Superior.

\section{LOS PRINCIPIOS GENERALES DEL ARTÍ́CULO 1 DEL ESTATUTO DEL CONSUMIDOR COLOMBIANO}

En atención a que los principios generales cumplen una función creativa, integradora e interpretativa, se procede a examinar los principios que orientan el régimen de protección al consumidor colombiano, consagrados en el artículo 1 del EC.

\section{A. El libre ejercicio de los derechos de los consumidores}

El artículo 1 del EC empieza por indicar que "Esta ley tiene como objetivos proteger, promover y garantizar la efectividad y el libre ejercicio de los derechos de los consumidores [...]". De modo que la defensa e impulso de la libertad en el empleo de los derechos de los usuarios se instituye en el primer pilar de su sistema de protección.

Vale entonces señalar que la libertad en el ordenamiento jurídico colombiano se configura, de una parte, como un objetivo y fin esencial del Estado. Debe recordarse que el Preámbulo de la Constitución Política de 1991, por demás con carácter vinculante, señala que ese cuerpo normativo se promulga " $[. .$.$] con el fin de for-$ talecer la unidad de la Nación y asegurar a sus integrantes la vida, la convivencia, el trabajo, la justicia, la igualdad, el conocimiento, la libertad y la paz, dentro de un marco jurídico, democrático y participativo que garantice un orden político, económico y social justo, y comprometido a impulsar la integración de la comunidad latinoamericana $[. .]$.$" .$

Así, en términos de la Corte Constitucional "el Preámbulo de la Constitución incorpora, mucho más allá de un simple mandato 
específico, los fines hacia los cuales tiende el ordenamiento jurídico; los principios que inspiraron al Constituyente para diseñar de una determinada manera la estructura fundamental del Estado; la motivación política de toda la normatividad; los valores que esa Constitución aspira a realizar y que trasciende la pura literalidad de sus artículos. El Preámbulo da sentido a los preceptos constitucionales y señala al Estado las metas hacia las cuales debe orientar su acción; el rumbo de las instituciones jurídicas"13.

Con fundamento en ello, y desde otra perspectiva, la libertad constituye un derecho fundamental, consagrado en el artículo 13 Superior, el cual se proyecta en diferentes ámbitos de la persona - personalidad, movilidad, conciencia, culto, expresión, oficio, enseñanza $y$, por supuesto, ejercicio de derechos ${ }^{14}$.

En lo que respecta a la libertad en el ejercicio de los derechos, el artículo 95 de la Constitución establece con claridad: "el ejercicio de los derechos y libertades reconocidos en esta Constitución implica responsabilidades", de manera que aunque hay una garantía en el reconocimiento y protección de los derechos de las personas, su amparo y salvaguardia deben estar sujetos al justo equilibrio entre el cumplimiento de los deberes y obligaciones en el caso específico, y las facultades bajo resguardo ${ }^{15}$.

Al amparo de ese entendimiento, en el campo del Derecho del Consumo debe indicarse que sin perjuicio de que la libertad en el ejercicio de los derechos de los consumidores se configura en un principio cardinal del régimen de protección al usuario, su concreción está íntimamente enlazada al cumplimiento de deberes y obligaciones que la normativa de la Ley 1480 le establece al consumidor.

De este modo, el principio de libre ejercicio de facultades del usuario implica que el consumidor cuenta con la autoridad de elegir,

13 Colombia, Corte Constitucional, Sentencia C-542-10, 30 de junio de 2010, magistrado ponente Jorge Iván Palacio-Palacio. Disponible en: http://www.corteconstitucional.gov.co/relatoria/2010/c-542-10. htm

14 Ver, entre otros, los artículos 16, 18, 19, 20, 26, 28 de la Constitución Política de Colombia de 1991. Colombia, Constitución Política, versión corregida 116 Gaceta Constitucional, 20 de julio de 1991. Disponible en: http://www.secretariasenado.gov.co/senado/basedoc/constitucion_politica_1991. html

15 "Una correcta aplicación de las normas constitucionales debe reflejarse en el equilibrio entre derechos y deberes, merced a la ponderación de los factores que inciden en la circunstancia específica, dentro de los principios generales de justicia, seguridad y equidad". Colombia, Corte Constitucional, Sentencia C-657-97, 3 de diciembre de 1997, magistrado ponente José Gregorio Hernández-Galindo. Disponible en: http://www.corteconstitucional.gov.co/relatoria/1997/c-657-97.htm 
decidir y ejercer el derecho que dentro del régimen de protección al consumidor satisfaga sus necesidades sociales, económicas y jurídicas. Pero, correlativamente, las demás personas, públicas y/o privadas, tienen la obligación de permitir la efectividad de esa potestad en cabeza del usuario.

Todo ello en el marco, como se anticipaba, de la ponderación entre el acatamiento de los deberes, responsabilidades y obligaciones concretas que les son exigibles al consumidor que, vale anotar, no se agotan con el sometimiento a rajatabla de lo prescrito en el artículo 3 del EC. En efecto, los derechos de los usuarios - garantía, retracto, información, etc.- demandan el cumplimiento de deberes y obligaciones por parte de los consumidores, que deben ser coherentes y armónicos con el ejercicio de la facultad que pretenden desempeñar.

De ahí que pueda afirmarse que el principio del libre ejercicio de los consumidores tenga una doble dimensión. Primero, la facultad subjetiva con la que cuenta el usuario para disponer de los derechos que lo protegen; $y$, segundo, el cumplimiento objetivo de las responsabilidades, deberes $\mathrm{u}$ obligaciones que el ejercicio de ese derecho exige.

En ese sentido, la tarea normativa, interpretativa e integradora que tiene el principio sub examine se enmarca en la protección efectiva de la autónoma e independiente potestad del consumidor de disponer de sus derechos, pero también de acatar las responsabilidades que cada una de dichas facultades envuelve.

\section{B. El respeto a la dignidad y los intereses económicos de los usuarios}

Aunque puede parecer muy básico, debe advertirse que dicho postulado consagra, por una parte, el respeto a la dignidad de los usuarios y, de otra, el respeto a sus intereses económicos, como premisas independientes, pero relacionadas. Con fundamento en ello se estudiarán separadamente para luego proceder a su entendimiento conjunto.

El respeto a la dignidad de los consumidores. Como lo ha considerado la Corte Constitucional de manera reiterada, el concepto de dignidad humana "(i) es un principio fundante del ordenamiento 
jurídico y en este sentido tiene una dimensión axiológica como valor constitucional, (ii) es un principio constitucional y (iii) tiene el carácter de derecho fundamental autónomo"16. En ese sentido, la alta corporación, al estudiar las implicaciones de la dignidad como principio y derecho, ha considerado que "En el contexto de la dignidad humana como principio y derecho la Corte ha sostenido que la protección de la Carta se refiere a '(i) la autonomía o posibilidad de diseñar un plan vital y de determinarse según sus características (vivir como se quiere), (ii) ciertas condiciones materiales concretas de existencia (vivir bien), (iii) la intangibilidad de los bienes no patrimoniales, integridad física e integridad moral (vivir sin humillaciones)"'17.

Esas tres dimensiones citadas - (i) vivir como se quiere; (ii) vivir bien; y (iii) vivir sin humillaciones - se extienden a su vez a los consumidores, primero como personas titulares de derechos al amparo de la Carta Política, pero segundo por disposición expresa del artículo 1 sub examine. De modo que el respeto a la dignidad del usuario supone inexorablemente la facultad que tiene el consumidor de exigir de los demás un trato acorde a su condición; implica la garantía del libre desarrollo de la vida del consumidor, individual y organizativamente considerado, en el marco de la sociedad de mercado y consumo que lo envuelve. Incluye a su vez la capacidad con la que cuenta el usuario para elegir y ejercer sus derechos, tal como se tuvo la oportunidad de analizar en el punto inmediatamente anterior.

En efecto, la condición de consumidor no solo arropa la calidad jurídica dispuesta en nuestro entorno bajo el numeral 3 del artículo 5 del EC. La aptitud de usuario o consumidor entraña una categoría social y económica que, además de ser protegida por el ordenamiento, implica una serie de condiciones frente a esos dos grandes escenarios.

16 Colombia, Corte Constitucional, Sentencia C-355-06, 10 de mayo de 2006, magistrados ponentes Jaime Araújo-Rentería, Clara Inés Vargas-Hernández. Disponible en: http://www.corteconstitucional. gov.co/relatoria/2006/c-355-06.htm

17 Colombia, Corte Constitucional, Sentencia T-917-06, 9 de noviembre de 2006, magistrado ponente Manuel José Cepeda-Espinosa. Disponible en: http://www.corteconstitucional.gov.co/ relatoria/2006/t-917-06.htm. También: Colombia, Corte Constitucional, Sentencia T-881-02, 17 de octubre de 2002, magistrado ponente Eduardo Montealegre Lynett. Disponible en: http://www. corteconstitucional.gov.co/relatoria/2002/t-881-02.htm 
De ahí que así como se habla de dignidad humana, pueda también referirse a la dignidad del consumidor, teniendo siempre presente que el vivir como se quiere, vivir bien y vivir sin humillaciones en el plano del usuario requiere el entendimiento multidimensional, "poliédrico" como diría nuestra Corte Constitucional, que concentra la varias veces enunciada figura del consumidor.

Los intereses económicos de los usuarios. Íntimamente atados a los elementos multidimensionales que configuran la categoría de consumidor, el legislador colombiano, mediante el artículo 1 del EC, consagró de manera expresa el carácter económico que, sin lugar a dudas, define a los usuarios.

Precisamente, el principio del respeto a los intereses económicos de los consumidores da razón de la trascendental proyección normativa que tiene la actitud de los usuarios en el mercado, más allá de un simple entendimiento legal. Tanto que, como se observa, el EC dispone que el respeto a los intereses económicos es un principio jurídico que ilustra a todo el ordenamiento de consumo.

Así, cuando se habla de intereses económicos se hace alusión a aquellas motivaciones que mandan al consumidor satisfacer sus necesidades, previendo la relación que el usuario pueda tener con $x$ o $y$ producto dispuesto en el mercado ${ }^{18}$. Consumir, en definitiva, no es más que la manifestación externa de la sujeción de la acción humana a la estimulación interna de satisfacer.

De manera que el principio bajo estudio propugna por el acatamiento y consideración, por parte de los demás actores, de la libertad de decisión que tiene el usuario para atender sus requerimientos al amparo de su autónoma voluntad.

Y no puede ser de otra manera. En atención a lo hasta aquí estudiado, solo cuando el consumidor cuenta con el respeto de sus motivaciones para consumir, se cumplen los principios de libre ejercicio de derechos y dignidad, amparados ellos en la voluntad independiente del usuario. Todo ello en concordancia con un mercado en libertad por el que ha optado el constituyente colombiano — artículo 333 de la Constitución Política de 1991—.

18 El profesor italiano Carnelutti enseña que "son actos económicos aquellos mediante los cuales tratan los hombres de satisfacer sus necesidades". Francesco CARnelutti, Cómo nace el derecho, 11 (Editorial Temis, Bogotá, 2008). 


\section{La protección de los consumidores frente a los riesgos para su salud y seguridad}

Indudablemente, la masificación de los bienes y servicios en el mercado es la correlativa masificación de los riesgos proclives a generar perjuicios en los consumidores.

En efecto, el constante desarrollo de la revolución industrial ha significado la intermediación fabril en la construcción y elaboración de los productos $\mathrm{y}$, en adición, el uso de elementos químicos y tecnológicos en los procesos de industria y comercialización que hacen cada vez más complejo el entendimiento de los bienes objeto de consumo.

Como es bien sabido, el desenvolvimiento de las máquinas, los elementos sintéticos y los productos genéticamente modificados o transgénicos son cada vez más comunes en la composición de los productos finales que se comercializan. Por ese motivo, el consumidor, además de tener derecho a una información suficiente y atinada sobre los productos, cuenta con una regla fundamental que propugna por la defensa de su salud y seguridad.

El principio de la protección de los consumidores frente a los riesgos para su salud y seguridad no solo tiene una consagración legal, sino adicionalmente constitucional por vía de los denominados derechos colectivos, lo que implica un amparo y reconocimiento superior. Al respecto debe recordarse que el inciso 2 del artículo 78 de nuestra Constitución señala: "Serán responsables, de acuerdo con la ley, quienes en la producción y en la comercialización de bienes y servicios, atenten contra la salud, la seguridad y el adecuado aprovisionamiento a consumidores y usuarios"19.

19 La Corte Constitucional colombiana, al estudiar las implicaciones de este derecho y su íntima relación con la información, ha considerado: "No puede exigir quien ha contaminado un producto alimenticio o utilizado en su fabricación una sustancia química prohibida, que sobre esto se mantenga el sigilo a fin de no perder clientes, como si el nivel de ventas debiera mantenerse o incrementarse a toda costa sin tener en cuenta la salud de los consumidores, y por fuera de toda consideración acerca de las estrategias lícitas o ilícitas empleadas para ello. El derecho a la ganancia es legítimo y se garantiza por el derecho; pero no es tan absoluto como para asegurarlo a quien se lucra envenenando a la población. (...) No puede olvidarse que los productores y comercializadores de bienes y servicios no pueden atentar contra la salud y la seguridad de los consumidores y usuarios (C.P. art. 78). Tampoco puede desvalorizarse el deber consagrado en el artículo 95-2 de la C.P.: 'Obrar conforme al principio de solidaridad social, respondiendo con acciones humanitarias ante situaciones que pongan en peligro la vida o la salud de las personas'. (...) los miembros de la comunidad, tienen el derecho constitucional de acceder a la información detallada y relevante sobre la composición y efectos de los bienes y servicios que ingresan al mercado y, desde luego, en los distintos ámbitos participativos 
Sin embargo, la consagración constitucional y legal del derecho y principio general de consumo tiene otras grandes implicaciones normativas - función creadora-, proyectado principalmente por lo dispuesto en el artículo 78 Superior. De una parte, el régimen de garantía establecido entre los artículos 7 y 17 del EC y, de la otra, el importantísimo sistema legal de la responsabilidad por productos defectuosos, reglado entre los artículos 20 y 22 del EC. Ellos, primordialmente y en línea con lo anterior, dirigidos a salvaguardar la vida, la salud y seguridad de los usuarios.

En lo que atañe al segundo, esto es la responsabilidad por productos defectuosos, la Sala de Casación Civil de la Corte Suprema de Justicia, mediante la sentencia del 30 de abril de 2009, amparada en el inciso 2 del artículo 78 de la Carta Política indicó: "Trátase pues, de una franca y rotunda alusión, de índole constitucional, a un régimen de responsabilidad de productores y distribuidores, derivado, ya no de las deficientes o irregulares condiciones de idoneidad y calidad de los productos que manufacturan o mercantilizan, sino de los actos que lesionan la salud y seguridad de usuarios y consumidores. Desde esa perspectiva, esta última prescripción, complementa y perfecciona el conjunto de salvaguardas de la parte débil de la relación de consumo" 20 .

tienen también derecho a incidir también sobre los tipos de producción y consumo que sean acordes con un desarrollo sostenible y con la protección de su salud y seguridad integral". Colombia, Corte Constitucional, Sentencia T-333-00, 23 de marzo de 2000, magistrado ponente Eduardo CifuentesMuñoz. Disponible en: http://www.corteconstitucional.gov.co/relatoria/2000/t-333-00.htm

20 Colombia, Corte Suprema de Justicia, Sala de Casación Civil, Expediente 2589931939921999 00629 01, 30 de abril de 2009, magistrado ponente Pedro Octavio Munar-Cárdenas. También sostuvo la Corte en sentencia del 7 de febrero de 2007 "puede afirmarse que la tutela efectiva de los intereses de los consumidores y usuarios, habida cuenta de la posición de inferioridad o debilidad que ordinariamente ocupan en el tráfico mercantil y la asimetría que caracteriza sus relaciones jurídico-económicas con los distribuidores o fabricantes, no puede verse restringida o limitada por el principio de la relatividad de los contratos, cuyo alcance, por cierto, tiende cada vez a ser morigerado por la doctrina jurisprudencial, puesto que, con independencia del vínculo jurídico inmediato que ellos pudieran tener con el sujeto que les enajenó o proveyó un determinado bien o servicio, las medidas tuitivas propias de su condición han de verse extendidas hasta la esfera del productor o fabricante, como quiera que este es quien ha gestionado, controlado o dirigido el diseño y elaboración del producto, entre otros aspectos, así como ha determinado ponerlo en circulación o introducirlo en el mercado, adquiriendo, por contera, un compromiso en torno a la calidad e idoneidad del mismo, por lo que, desde luego, no puede resultar ajeno o indiferente a sus eventuales defectos o anomalías, ni a los peligros o riesgos que estos pudieran generar, como tampoco a las secuelas de orden patrimonial que llegaren a afectar a su destinatario final - consumidores o usuarios-o a terceros, con lo que queda claramente establecida una 'responsabilidad especial' de aquel frente a estos - ex constitutione - , que los habilita para accionar directamente contra el fabricante en orden a hacer efectivas las garantías a que hubiere lugar o a reclamar el resarcimiento de los daños que les fueron irrogados, sin que tal potestad pueda ser coartada por la simple inexistencia de un 
Así las cosas, los fallos anteriormente citados comprueban la presencia generalizada en el ordenamiento colombiano del principio de la protección de los consumidores frente a los riesgos para su salud y seguridad, sobre todo en atención a su notable influencia antes de la promulgación del EC, la Ley 1480 de 2011. De ahí que pueda sostenerse que el principio de la defensa a la salud y seguridad de los usuarios en el EC sea consecuencia de la abstracción normativa efectuada esencialmente a partir del derecho reconocido en el inciso 2 del artículo 78 de la Carta Política.

Este hecho no es para nada fortuito. Sin lugar a equívocos, la presencia constitucional del derecho-principio significa, primero, una comprensión bifronte de la protección. De un lado, el derecho y la correlativa obligación de los productores, distribuidores y comercializadores de no generar riesgos y daños en los consumidores $y$, de otro, un axioma dirigido a influir y entender el ordenamiento general, no solo en el campo de consumo, en el sentido de que debe ampararse la salud y seguridad de los usuarios. Pero adicional a ello, segundo, la presencia constitucional envuelve la influencia del principio en todos los rincones del ordenamiento jurídico colombiano y, en particular, en la cadena de producción, importación, distribución y comercialización.

\section{El acceso de los consumidores a una información adecuada, de acuerdo con los términos de esta ley, que les permita hacer elecciones bien fundadas}

La información es un presupuesto fundamental para el acto de consumo. No solo ello, es un elemento estructural para el consumidor educado y razonable, esencial para el entendimiento del estándar del llamado usuario medio. Solo el usuario informado cuenta con la capacidad suficiente para ejercer sus derechos.

Implica la obligación de informar que una de las partes - el productor y/o comercializador-cuenta con los datos suficientes y privilegiados del producto y el negocio objeto de celebración. De manera que el consumidor, objetivamente profano sobre el bien o servicio, requiere las referencias necesarias, habilitadas y

vínculo de linaje contractual (...)”. Corte Suprema de Justicia, Sala de Casación Civil, Expediente 1999-00087-01, 7 de febrero de 2007. 
suministradas por ese productor o comercializador entendido, para que él pueda disponer del producto de manera racional y con plena voluntad.

En ese sentido, a partir del principio bajo examen se desprende el derecho de los consumidores a recibir información, comprendida bajo el propio EC - numeral 7, artículo 5-como "todo contenido y forma de dar a conocer la naturaleza, el origen, el modo de fabricación, los componentes, los usos, el volumen, peso o medida, los precios, la forma de empleo, las propiedades, la calidad, la idoneidad o la cantidad, y toda otra característica o referencia relevante respecto de los productos que se ofrezcan o pongan en circulación, así como los riesgos que puedan derivarse de su consumo o utilización".

Así, señala el numeral 1.3 del artículo 3 del EC que el usuario tiene derecho a "obtener información completa, veraz, transparente, oportuna, verificable, comprensible, precisa e idónea respecto de los productos que se ofrezcan o se pongan en circulación, así como sobre los riesgos que puedan derivarse de su consumo o utilización, los mecanismos de protección de sus derechos y las formas de ejercerlos".

Efectivamente, la Corte Constitucional colombiana ha reconocido a lo largo de su jurisprudencia que "[...] de la esencia de los derechos de los consumidores, en los términos constitucionales (...), algunos aspectos que deberían ser tomados en consideración por el Legislador, bajo el mandato de protección (...). Entre otros, están por ejemplo: (...) (iii) El acceso a la información necesaria para la toma de decisiones ilustradas de consumo, es un aspecto que también debe ser regulado y del que hablaremos más adelante [...]"21.

De ahí que, a partir de esta facultad, se desprenda el régimen de la información previsto entre los artículos 23 y 28 del EC, que consagran, entre otras, la responsabilidad de los productores y proveedores por la falta de información, y la información mínima a suministrar.

Así, no se trata de que el consumidor tenga un simple acceso a la información sobre los productos. La información en el ámbito

21 Colombia, Corte Constitucional, Sentencia C-583-15, 8 de septiembre de 2015, magistrada ponente Gloria Stella Ortiz-Delgado. Disponible en: http://www.corteconstitucional.gov.co/ relatoria/2015/c-583-15.htm 
de consumo está apellidada por la veracidad, la imparcialidad, la suficiencia, la idoneidad y la claridad. No en vano la Corte Constitucional patria ha indicado, al analizar el asunto de la información en el campo del consumidor financiero, que la complejidad de los conceptos negociales y el estado de indefensión en que se encuentran por lo general los consumidores, "hacen de la información una de las herramientas claves para empoderar al ciudadano en su ejercicio contractual" 22 . De manera que: “[...] cualquier restricción injustificada al acceso a la información debe entenderse como una práctica abusiva, propiciada por el poder dominante del que gozan los productores" 23 .

En definitiva, a partir de lo analizado en la sentencia C-583-15, puede entonces sostenerse que el principio de acceso a la información cumple varias funciones y expresiones en nuestro ordenamiento: (i) garantiza el derecho de los consumidores a la información relevante sobre los productos y le da sentido a su derecho a la información; (ii) habilita a los consumidores a elegir de una manera libre los productos que deseen consumir, conforme a su propia orientación de vida, con lo cual respeta el núcleo del derecho a elegir, que compete al consumidor y que está ligado claramente a la expresión de su libre desarrollo de la personalidad; (iii) garantiza la protección y prevención en materia de salud, al admitir los riesgos

22 Colombia, Corte Constitucional, Sentencia T-136-13, 13 de marzo de 2013, magistrado ponente Jorge Iván Palacio-Palacio. Disponible en: http://www.corteconstitucional.gov.co/relatoria/2013/t-136-13. htm

23 Ibídem. En idéntico sentido el Consejo de Estado, mediante la sentencia del 22 de junio de 2006, destacó la importancia de la información para la toma de decisiones en al ámbito de consumo. Sobre este asunto manifestó la alta corporación: "Conviene reiterar que la protección de los derechos de los consumidores, pasa necesariamente por una adecuada información sobre los bienes y servicios que se ofrecen en el mercado, ya que con base en ella y atendiendo las circunstancias personales de todo orden, sus intereses y necesidades es que decide sobre su adquisición o no, con lo cual está diciendo que esa publicidad incide y condiciona la conducta del consumidor, la medida o grado de satisfacción de sus necesidades y su calidad de vida, considerada individual y socialmente, y en ese orden el legislador ha querido eliminar toda posibilidad de que esa incidencia se dé en perjuicio del consumidor, más cuando la doctrina y la jurisprudencia ha puesto de presente que este es la parte frágil y débil de la relación negocial del mercado, a lo que la Sala agrega que es el destinatario y objeto de toda actividad económica; y que esta, a fin de asegurar que esté al servicio de la persona humana, ha sido sometida por el Constituyente y el Legislador colombiano de tiempo atrás, a una función social, es decir, que sin perjuicio de la libertad de empresa y el ánimo de lucro que pueda motivar, debe estar al servicio del ser humano, de su calidad de vida y de su derecho a la vida digna" (itálicas fuera de texto). Colombia, Consejo de Estado, Sala de lo Contencioso Administrativo, Sección Primera, Sentencia 250002324000200200540 01, consejero ponente Rafael E. Ostau de Lafont Pianeta, 22 de junio de 2006. Disponible en: http://181.57.206.9:8080/WebRelatoria/ce/index. xhtml 
presuntos o eventuales ligados con aspectos del desarrollo de estos productos que son desconocidos hasta el momento por la sociedad, sobre la base del principio de precaución; (iv) cumple una función instrumental, al facilitar el seguimiento a estos productos por parte de las autoridades correspondientes; (v) el derecho a acceder a esta información garantiza la transparencia en la información que se obtiene respecto a los productores y contribuye a disminuir el desequilibrio entre productores y consumidores que precisamente busca superar el Derecho de Consumo; y (vi) asegura la transparencia frente a las autoridades públicas con respecto a los datos relacionados con los productos.

Por otra parte, el principio bajo examen, aunado a los derechos constitucionales, tiene otras dos manifestaciones importantes. De un lado, el derecho de los consumidores a informar - numeral 1.10, artículo 3 del EC - y, de otro, el deber de los usuarios, obligación concreta, de informarse sobre los productos, en particular de su calidad, instrucciones, uso, conservación e instalación - numeral 2.2, artículo 3 del EC-.

En lo que refiere al primero, debe recordarse que en virtud de lo dispuesto por el artículo 20 Superior "Se garantiza a toda persona la libertad de expresar y difundir su pensamiento y opiniones, la de informar y recibir información veraz e imparcial, y la de fundar medios masivos de comunicación [...]”. De este modo, en razón al citado artículo 20 de nuestra Constitución, así como al principio bajo análisis, los usuarios, sus organizaciones y las autoridades públicas tienen la facultad de acceder a los medios de comunicación, para informar, divulgar y educar sobre el ejercicio de sus derechos. Aunque este tipo de potestad se relaciona primigeniamente con la puesta en marcha de las garantías y prerrogativas a favor del consumidor, también está íntimamente relacionada con el acceso a una información veraz, clara y suficiente que les permita a los usuarios, en el marco del conocimiento de sus derechos, consumir con discernimiento. La información en materia de consumo y los datos que se transmiten no pueden agotarse en el producto objeto de negocio, debe también alcanzar los derechos pre, pos y extracontractuales que le permitan al usuario saber de las facultades con las que cuenta para exigir las pretensiones que puedan derivar de su vínculo con el producto, el productor o el distribuidor. 
Ahora, en lo que respecta al segundo, esto es, el deber que tienen los consumidores de informarse sobre el producto, puede indicarse que el citado deber previsto en el numeral 2.2 del artículo 3 del EC se ajusta al principio de acceso a la información que se estudia y al postulado de la educación al consumidor que se verá a continuación. En efecto, el hecho de ofrecer y brindar la información a los usuarios requiere también un mínimo esfuerzo y diligencia por parte de los consumidores, dirigido a aprehender y entender los datos - comprensibles, veraces, imparciales - que se le suministran sobre el producto. Este hecho está en concordancia con el estándar del consumidor medio, que presupone un usuario acucioso y entendido de manera razonable de las características generales del producto.

De manera que puede sostenerse con claridad certera que el acceso y el suministro de la información, aunque se rige por lo dispuesto en las normas del EC — artículos 23 a 28 de ese cuerpo normativo-, debe partir en el caso concreto del estándar de consumidor medio o razonable destinatario del producto para esclarecer en esa hipótesis cuál información es pertinente. Debe recordarse y subrayarse que las reglas dispuestas en los artículos 23 y 24 del EC son disposiciones de mínimos y no de máximos en materia de información. De modo que puede ser admisible y necesario brindar datos que siendo exigibles en el caso definido, en atención al consumidor medio respectivo, sobrepase la lista dispuesta por la normativa del EC.

\section{E. La educación del consumidor}

Formar e instruir a los usuarios en sus derechos, obligaciones y adicionalmente sobre los elementos necesarios y relevantes del mercado y los productos objeto de consumo se instituye en un principio cardinal del EC.

De manera que la ilustración a los consumidores es uno de los lineamientos guía para la creación y comprensión de las normas que los protegen, pero adicionalmente para incentivar su desarrollo cognoscitivo, que lleve a tener usuarios cada vez más informados, enterados, razonables, que no es otra cosa que consumidores educados. 
En efecto, a raíz de dicho postulado, el numeral 1.11 del artículo 3 del EC indica que es facultad de los usuarios " [...] recibir educación sobre los derechos de los consumidores, formas de hacer efectivos sus derechos y demás materias relacionadas". De modo que la educación, comprendida como el incentivo hacia el desarrollo o perfeccionamiento de las facultades intelectuales de las personas, no se circunscribe, en este caso, a los derechos y obligaciones jurídicas que les atañen a los consumidores, envuelve además aquellos elementos relacionados, a manera de ejemplo, con las formas de publicidad, el producto, sus elementos, su proceso de fabricación, su forma de uso y/o instalación, el sector de la población a que va dirigido el bien o servicio - target - , las expectativas de seguridad del fabricante, que además de implicar el suministro de información — principio y derecho diferencial al que se estudia-, requiere un grado de formación hacia los consumidores.

Por ese motivo, debe indicarse con certeza que no puede preverse el cumplimiento al principio y derecho de educación al consumidor sin que haya un correlativo derecho u obligación de suministro de información que permita a los usuarios enterarse y apropiarse de sus derechos, obligaciones y condiciones de relación con el producto, su fabricante y/o expendedor.

Así, se reitera y subraya, el principio y el derecho bajo examen no se allana a la instrucción acerca de las facultades y obligaciones de orden legal que les corresponden a los consumidores, el principio de la educación al consumidor va mucho más allá al procurar usuarios consabidos en el régimen y acto socioeconómico de consumo - lo que envuelve las condiciones de mercado, el entendimiento práctico, que no estrictamente normativo, de la publicidad, la garantía, el retracto, etc. - para que conciba un estándar de consumidor medio razonable cada vez más alto.

\section{F. La libertad de constituir organizaciones de consumidores y la oportunidad para esas organizaciones de hacer oír sus opiniones}

La libertad de constituir organizaciones de consumidores como principio dentro del EC es, sin lugar a equívocos, producto de la abstracción normativa derivada tanto del derecho fundamental de 
la libre asociación consagrado en el artículo 38 de la Constitución Política de 1991, como del derecho colectivo a la participación de las organizaciones de consumidores y usuarios en el estudio de las disposiciones que les conciernen, dispuesto en el artículo 78 Superior.

Proyectado al ámbito de las organizaciones de consumo, la libertad de constituir organizaciones, ligas o asociaciones de consumidores envuelve (i) el derecho de asociarse y de escoger la asociación, pero también (ii) el derecho a no ser obligado directa o indirectamente a formar parte de una colectividad ${ }^{24}$. Por ese motivo, los numerales 1.8 y 1.9 del artículo 3 del EC establecen con claridad que los usuarios tienen la facultad de organizarse y colegiarse para proteger sus derechos e intereses y, adicionalmente, la potestad de hacerse representar por sus organizaciones para la solución de las reclamaciones sobre consumo de bienes y servicios.

El reconocimiento legal de estas facultades, emanadas del principio que se estudia, no solo se concentra en la protección del derecho objetivo, colectivo e individual, reglado en el régimen de consumo; arropa además la participación de los consumidores en la etapa de construcción normativa y la delineación de políticas públicas, mediante órganos colegiados. De manera que la Constitución y la Ley han querido otorgarles a los usuarios no solo instrumentos reactivos a la transgresión de sus derechos, sino herramientas preventivas de intervención que les permitan, antes de la producción

24 Sobre el derecho de asociación, la Corte Constitucional ha indicado: "El derecho o libertad de asociación contiene en sí mismo dos aspectos complementarios: uno positivo (el derecho a asociarse), y otro negativo (el derecho a no ser obligado directa o indirectamente a formar parte de una asociación determinada)". Estas dos dimensiones integran la estructura del derecho de asociación que se enmarca en la cláusula general de libertad, y guarda estrecha relación con la garantía de la autonomía de las personas (artículo 16). En ese orden de ideas, el primer aspecto del derecho de asociación — de carácter positivo - puede ser descrito como la "facultad de toda persona para comprometerse con otras en la realización de un proyecto colectivo, libremente concertado, de carácter social, cultural, político, económico, etc. a través de la conformación de una estructura organizativa, reconocida por el Estado", con capacidad para ceñirse a los requisitos y trámites legales instituidos para el efecto y operar en el ámbito jurídico. El segundo, de carácter negativo, conlleva la facultad de todas las personas de "abstenerse de formar parte de una determinada asociación y la expresión del derecho correlativo a no ser obligado, ni directa ni indirectamente a ello, libertad que se encuentra protegida por los artículos 16 y 38 de la Constitución”. Colombia, Corte Constitucional, Sentencia C-978-10, 1 de diciembre de 2010, magistrado ponente Luis Ernesto Vargas-Silva. Disponible en: http://www. corteconstitucional.gov.co/relatoria/2010/c-978-10.htm. También: Colombia, Corte Constitucional, Sentencia C-384-00, 5 de abril de 2000, magistrado ponente Vladimiro Naranjo-Mesa. Disponible en: http://www.corteconstitucional.gov.co/relatoria/2000/c-384-00.htm. Colombia, Corte Constitucional, Sentencia C-354-09, 20 de mayo de 2000, magistrado ponente Gabriel Eduardo Mendoza-Martelo. Disponible en: http://www.corteconstitucional.gov.co/relatoria/2009/c-354-09.htm 
legal, diseñar y construir junto a las autoridades las reglas que ordenarán sus relaciones.

En este contexto, surge una inquietud fundamental a partir de dos normas con contenido y jerarquías diferenciales. De un lado, el último aparte del inciso 3 del artículo 78 Superior señala un condicionamiento a la participación de las asociaciones de consumidores al indicar: "Para gozar de este derecho las organizaciones deben ser representativas y observar procedimientos democráticos internos". Y, por otro, el numeral 4 del artículo 1 del EC, que consagra el principio sub examine, no limita la forma y contenido de las asociaciones de usuarios para participar y expresar sus observaciones, al establecer de manera contundente que es un principio del régimen de consumo "La libertad de constituir organizaciones de consumidores y la oportunidad para esas organizaciones de hacer oír sus opiniones en los procesos de adopción de decisiones que las afecten".

Ante este escenario normativo, vale preguntarse: si el citado principio consagrado en el EC supera los condicionamientos dispuestos en el derecho colectivo de la Constitución Política de 1991 o, en otros términos, ¿la consagración del principio de libertad de participar de las asociaciones de consumidores del EC está supeditada a la condición constitucional referente a que estos organismos deben ser representativos y observar procedimientos democráticos internos?

El interrogante no es sencillo de resolver. Un derecho constitucional colectivo, de tercera generación, y un principio de Derecho puntual en el ámbito de la protección al consumidor - asunto que por demás no ha sido resuelto por la Corte Constitucional- se enfrentan. Sin embargo, y en atención a que la Constitución es norma de normas - artículo 4 Superior-, se considera que el principio de participación del que trata el numeral 4 del artículo 1 del EC debe ser entendido y puesto en práctica bajo la comprensión de que las asociaciones de consumidores, para intervenir en los asuntos de su interés, deben mostrarse representativas y contar con reglas democráticas internas. El Estado deberá entonces señalar los alcances de esa representatividad y las disposiciones democráticas a que hace alusión la Carta Política, que no están desarrolladas hasta el momento en las deposiciones de consumo. 


\section{G. La protección especial a los niños, niñas y adolescentes, en su calidad de consumidores, de acuerdo con lo establecido en el Código de la Infancia y la Adolescencia ${ }^{25}$}

En el ordenamiento colombiano, los niños, niñas y adolescentes cuentan una protección jurídica especial. El artículo 44 de la Constitución Política de 1991, además de reconocer este amparo y enlistar los derechos fundamentales de los niños, indica que "Los derechos de los niños prevalecen sobre los derechos de los demás".

Al respecto, la Corte Constitucional mediante la sentencia C-04404 ha indicado que "Las razones básicas de esta protección especial a los niños son: i) el respeto de la dignidad humana que, conforme a lo previsto en el artículo 1 de la Constitución, constituye uno de los fundamentos del Estado Social de Derecho colombiano; ii) su indefensión o vulnerabilidad, por causa del proceso de desarrollo de sus facultades y atributos personales, en su necesaria relación con el entorno, tanto natural como social, y, iii) el imperativo de asegurar un futuro promisorio para la comunidad, mediante la garantía de la vida, la integridad personal, la salud, la educación y el bienestar de los mismos"26.

La máxima corporación de lo constitucional también ha considerado que los niños cuentan con una protección reforzada. En esencia, porque los derechos fundamentales de los menores, enlistados en el artículo 44 de la Constitución, son protegidos de forma directa por vía de acción de tutela ${ }^{27}$.

De este modo, la Carta Política colombiana ha dispuesto, en relación con algunas categorías de personas - niños, niñas, adolescentes, consumidores, etc.- , un tratamiento jurídico de protección especial en atención a la fragilidad y situación de debilidad manifiesta que estas personas ostentan en el tráfico social

25 Colombia, Ley 1098 de 2006, por la cual se expide el Código de la Infancia y la Adolescencia, 46.446 Diario Oficial, 8 de noviembre de 2006. Disponible en: http://www.secretariasenado.gov. co/senado/basedoc/ley_1098_2006.html

26 Colombia, Corte Constitucional, Sentencia C-044-04, 27 de enero de 2004, magistrado ponente Jaime Araújo-Rentería. Disponible en: http://www.corteconstitucional.gov.co/relatoria/2004/c-044-04. htm

27 Colombia, Corte Constitucional, Sentencia T-380-07, 17 de mayo de 2007, magistrado ponente Jaime Araújo-Rentería. Disponible en: http://www.corteconstitucional.gov.co/relatoria/2007/t-380-07.htm 
y económico ${ }^{28}$. De ahí se explica la promulgación de un régimen específico de protección para los usuarios — reglado de forma fundante en el EC-, pero también unas normas especiales para los niños, niñas y adolescentes - instituidas principalmente en el Código de la Infancia y la Adolescencia-.

Así, en el campo del consumo como fenómeno social, económico y jurídico pueden confluir dos categorías de personas que muestran un grado mucho más profundo de indefensión y desequilibrio frente al productor y proveedor: el menor consumidor; que puede ser definido como la persona natural menor de 18 años de edad que como destinatario final, adquiere, disfruta o utiliza un producto para la satisfacción de una necesidad propia, privada, familiar o doméstica y empresarial cuando no esté ligada intrínsecamente a su actividad económica.

Por ese motivo, la Ley 1480 de 2011, previendo esta concurrencia y con fundamento en la citada protección especial tanto para menores como para consumidores, recoge en el principio dispuesto en el numeral 5 del artículo 1 del EC el lineamiento básico que debe guiar la creación de las normas de consumo, su interpretación e integración cuando se piensa o está frente a un niño, niña o adolescente consumidor.

Aunque hay solo dos manifestaciones puntuales del principio en el EC - artículo 28, derecho de información para niños, niñas y adolescentes, y artículo 58, protección de los niños, niñas y adolescentes en el comercio electrónico-, debe indicarse con razón meridiana que, en virtud de la naturaleza del principio que se examina, la defensa especial de los menores abarca todos y cada uno de los rincones del régimen de protección al usuario. De manera que aun cuando no están expresamente consagrados derechos puntuales sobre los niños, niñas y adolescentes consumidores en cada uno de los títulos del EC, en ellos debe proyectarse el principio de protección a los menores consumidores y velarse por la influencia de amparo de sus derechos fundamentales en el ámbito de consumo. Debe recordarse que se está frente a un principio general de Derecho de consumo.

28 Colombia, Corte Constitucional, Sentencia C-1141-00, 30 de agosto de 2000, magistrado ponente Eduardo Cifuentes-Muñoz. Disponible en: http://www.corteconstitucional.gov.co/ relatoria/2000/c-1141-00.htm 
Ahora, como lo señala el propio lineamiento, la defensa de los niños, niñas y adolescentes consumidores no solo está influida por sus derechos fundamentales establecidos en la Constitución, que en definitiva permea todo el orden jurídico, sino también por las reglas determinadas en el Código de la Infancia y la Adolescencia.

En efecto, el citado Código se instituye como el parámetro básico de entendimiento y protección de los intereses de los menores de edad. De modo que los derechos de los niños, niñas y adolescentes, las obligaciones de sus padres, familiares, entidades educativas y autoridades públicas para con ellos, deben leerse a su vez bajo la lupa de la relación de consumo y sus implicaciones, a efectos de dar contenido a la protección del menor en su posible condición de consumidor.

Se trata entonces de que la protección especial de los menores consumidores no solo se dé en sede de la relación de consumo productor, proveedor y menor usuario-. Los padres de familia, los familiares, la sociedad, las asociaciones de consumidores y las autoridades públicas cumplen un rol fundamental para ilustrar y resguardar a los menores en sus derechos y obligaciones en el campo de la sociedad de mercado y el acto de consumo. 


\section{CONCLUSIONES}

A manera de recapitulación, vale simplemente anotar que los principios generales del EC son verdaderas normas jurídicas que cumplen una función tripartita: la de informar, integrar e interpretar el sistema de reglas que mandan la protección de los consumidores, incluyendo aquellas especiales en materia de consumo. Adicionalmente, estos principios generales se expresan y manifiestan de forma clara y concreta en disposiciones constitucionales y legales propias de la Ley 1480, que ya han venido siendo desarrolladas por la jurisprudencia nacional.

Debe también advertirse que el artículo 1 del EC no agota los principios generales que son aplicables al Estatuto, sino que adicional a ello puede haber principios generales de Derecho que, no contrariando lo dispuesto en la Ley 1480, también le sean plenamente aplicables - la buena fe-.

Con todo, se muestra cómo a partir de los principios del EC el legislador colombiano ha querido estructurar la piedra angular del Derecho de Consumo colombiano, el cual, en razón a estas reglas del ser y del deber ser, comienza a entenderse, armonizarse y sistematizarse de mejor manea. 


\section{BIBLIOGRAFÍA}

\section{Libros}

Alexy, Robert, El concepto y la validez del derecho y otros ensayos (Editorial Gedisa, Barcelona, 1994).

Alexy, Robert, Teoría de los derechos fundamentales (Centro de Estudios Constitucionales, Madrid, 1993).

Bobbio, Norberto, Teoría general del derecho (Editorial Temis, Bogotá, 1987).

Carnelutti, Francesco, Cómo nace el derecho (Editorial Temis, Bogotá, 2008).

Castro y Bravo, Federico de, Derecho Civil de España, Tomo I (Ed. Instituto de Estudios Políticos, 1955).

Dímz-Picazo, Luis, Fundamentos del derecho civil patrimonial, II Relaciones obligatorias. Estudios y comentarios de legislación (Editorial Civitas, Madrid, 1996).

Dworkin, Ronald, Los derechos en serio (Editorial Planeta, Madrid, 1993).

García-Máynez, Eduardo, Filosofía del Derecho (Editorial Porrúa, México, 1983).

García-Máynez, Eduardo, Introducción al estudio del Derecho (Editorial Porrúa, México, 1984).

Mozos, José LuIs De Los, El principio de la buena fe, sus aplicaciones prácticas en el derecho civil español (Bosch Casa Editorial, Barcelona, 1965).

Ordoqui-Castilla, Gustavo, Buena fe contractual (Editorial Pontificia Universidad Javeriana, Grupo Editorial Ibáñez, Universidad Católica de Uruguay, Bogotá, 2012).

Pérez-Vives, Álvaro, Recursos de casación: en materia civil, penal y del trabajo (Editorial Librería Americana, Bogotá, Buenos Aires, 1946).

TAmayo-Jaramillo, Javier, Responsabilidad por productos defectuosos (Editorial Legis, Bogotá, 2016).

Tardío-Pato, José Antonio, Los principios generales del derecho: su aplicación efectiva como normas jurídicas (Bosch Casa Editorial, Barcelona, 2011).

VAlencia-Restrepo, Hernán, Nomoárquica, principialística jurídica o filosofía y ciencia de los principios generales del Derecho (Editorial Temis, Bogotá, 2005).

WieACKer, Franz, El principio general de la buena fe (José Luis CARro, trad., Editorial Civitas, Madrid, 1997).

\section{Revistas}

Hinestrosa, Fernando, De los principios generales del derecho a los principios generales del contrato, 5 Revista de Derecho Privado, Universidad Externado de Colombia, 5-22 (enero/junio 2000). 


\section{Tesis}

Salas-Salas, Nubia Cristina, El rol sistémico de los principios generales del derecho en el ordenamiento civil. Estudio de la jurisprudencia de la Sala Civil de la Corte Suprema de Justicia (Tesis de maestría, Universidad Nacional de Colombia Facultad de Derecho, Ciencias Políticas y Sociales, Bogotá, 2013). Disponible en: http://www.bdigital.unal.edu.co/9864/1/06700261.2013.pdf

\section{Normatividad colombiana}

Colombia, Constitución Política, versión corregida 116 Gaceta Constitucional, 20 de julio de 1991. Disponible en: http://www.secretariasenado.gov.co/senado/basedoc/ constitucion_politica_1991.html

Colombia, Decreto 410 de 1971, por el cual se expide el Código de Comercio [CCo], 33.339 Diario Oficial, 16 de junio de 1971. Disponible en: http://www.secretariasenado. gov.co/senado/basedoc/codigo_comercio.html

Colombia, Ley 57 de 1887, por la cual se expide el Código Civil [CC]. Disponible en: http://www.secretariasenado.gov.co/senado/basedoc/codigo_civil.html

Colombia, Ley 1098 de 2006, por la cual se expide el Código de la Infancia y la Adolescencia, 46.446 Diario Oficial, 8 de noviembre de 2006. Disponible en: http://www.secretariasenado.gov.co/senado/basedoc/ley_1098_2006.html

Colombia, Ley 1480 de 2011, por medio de la cual se expide el Estatuto del Consumidor [EC] y se dictan otras disposiciones, 48.220 Diario Oficial, 12 de octubre de 2011. Disponible en: http://www.secretariasenado.gov.co/senado/basedoc/ ley_1480_2011.html

Colombia, Aeronáutica Civil, Resolución 1375 de 2015, por la cual se modifican unos numerales del RAC 3 de los Reglamentos Aeronáuticos de Colombia, 49.541 Diario Oficial, 12 de junio de 2015. Disponible en: http://www.imprenta.gov.co/ diariop/diario2.nivel_3, http://www.avianca.com/es/Documents/resolucion-deretracto-y-desistimiento.PDF

\section{Proyectos de Ley}

Colombia, Proyecto de Ley 37/2014 Cámara, 74/2015 Senado, por medio de la cual se agrega un artículo a la Ley 1480 de 2011, con el fin de proteger al consumidor del servicio de transporte aéreo nacional de pasajeros, 827 Gaceta del Congreso, 9 de diciembre de 2014. Disponible en: http://servoaspr.imprenta.gov.co/gacetap/ gaceta.nivel_3

Colombia, informe de conciliación al Proyecto de Ley 74 de 2015 Senado, 37 de 2014 Cámara, por medio de la cual se establecen mecanismos de protección al usuario del servicio de transporte aéreo nacional de pasajeros y se dictan otras disposiciones, 434 Gaceta del Congreso, 16 de junio de 2016. Disponible en: http:// www.imprenta.gov.co/gacetap/gaceta.mostrar_documento?p_tipo $=123 \&$ p numero $=74 \&$ p_consec $=44926$ 


\section{Jurisprudencia colombiana}

Colombia, Consejo de Estado, Sala de lo Contencioso Administrativo, Sección Primera, Sentencia 250002324000200200540 01, consejero ponente Rafael E. Ostau de Lafont Pianeta, 22 de junio de 2006. Disponible en: http://181.57.206.9:8080/ WebRelatoria/ce/index.xhtml

Colombia, Corte Constitucional, Sentencia C-657-97, 3 de diciembre de 1997, magistrado ponente José Gregorio Hernández-Galindo. Disponible en: http://www. corteconstitucional.gov.co/relatoria/1997/c-657-97.htm

Colombia, Corte Constitucional, Sentencia C-384-00, 5 de abril de 2000, magistrado ponente Vladimiro Naranjo-Mesa. Disponible en: http://www. corteconstitucional.gov.co/relatoria/2000/c-384-00.htm

Colombia, Corte Constitucional, Sentencia C-1141-00, 30 de agosto de 2000, magistrado ponente Eduardo Cifuentes-Muñoz. Disponible en: http://www. corteconstitucional.gov.co/relatoria/2000/c-1141-00.htm

Colombia, Corte Constitucional, Sentencia C-044-04, 27 de enero de 2004, magistrado ponente Jaime Araújo-Rentería. Disponible en: http://www.corteconstitucional. gov.co/relatoria/2004/c-044-04.htm

Colombia, Corte Constitucional, Sentencia C-355-06, 10 de mayo de 2006, magistrados ponentes Jaime Araújo-Rentería, Clara Inés Vargas-Hernández. Disponible en: http://www.corteconstitucional.gov.co/relatoria/2006/c-355-06.htm

Colombia, Corte Constitucional, Sentencia C-354-09, 20 de mayo de 2000, magistrado ponente Gabriel Eduardo Mendoza-Martelo. Disponible en: http://www. corteconstitucional.gov.co/relatoria/2009/c-354-09.htm

Colombia, Corte Constitucional, Sentencia C-542-10, 30 de junio de 2010, magistrado ponente Jorge Iván Palacio-Palacio. Disponible en: http://www. corteconstitucional.gov.co/relatoria/2010/c-542-10.htm

Colombia, Corte Constitucional, Sentencia C-978-10, 1 de diciembre de 2010, magistrado ponente Luis Ernesto Vargas-Silva. Disponible en: http://www. corteconstitucional.gov.co/relatoria/2010/c-978-10.htm

Colombia, Corte Constitucional, Sentencia C-896-12, 31 de octubre de 2012, magistrado ponente Mauricio González-Cuervo. Disponible en: http://www. corteconstitucional.gov.co/RELATORIA/2012/C-896-12.htm

Colombia, Corte Constitucional, Sentencia C-583-15, 8 de septiembre de 2015, magistrada ponente Gloria Stella Ortiz-Delgado. Disponible en: http://www. corteconstitucional.gov.co/relatoria/2015/c-583-15.htm

Colombia, Corte Constitucional, Sentencia T-333-00, 23 de marzo de 2000, magistrado ponente Eduardo Cifuentes-Muñoz. Disponible en: http://www. corteconstitucional.gov.co/relatoria/2000/t-333-00.htm

Colombia, Corte Constitucional, Sentencia T-881-02, 17 de octubre de 2002, magistrado ponente Eduardo Montealegre Lynett. Disponible en: http://www. corteconstitucional.gov.co/relatoria/2002/t-881-02.htm

Colombia, Corte Constitucional, Sentencia T-917-06, 9 de noviembre de 2006, magistrado ponente Manuel José Cepeda-Espinosa. Disponible en: http://www. 
corteconstitucional.gov.co/relatoria/2006/t-917-06.htm

Colombia, Corte Constitucional, Sentencia T-380-07, 17 de mayo de 2007, magistrado ponente Jaime Araújo-Rentería. Disponible en: http://www.corteconstitucional. gov.co/relatoria/2007/t-380-07.htm

Colombia, Corte Constitucional, Sentencia T-136-13, 13 de marzo de 2013, magistrado ponente Jorge Iván Palacio-Palacio. Disponible en: http://www. corteconstitucional.gov.co/relatoria/2013/t-136-13.htm

Colombia, Corte Suprema de Justicia, Sala de Casación Civil, 19 de agosto de 1935.

Colombia, Corte Suprema de Justicia, Sala de Casación Civil, 30 de octubre de 1935.

Colombia, Corte Suprema de Justicia, Sala de Casación Civil, 29 de octubre de 1936.

Colombia, Corte Suprema de Justicia, Sala de Casación Civil, XLIV Gaceta Judicial, 19 de noviembre de 1936.

Colombia, Corte Suprema de Justicia, Sala de Casación Civil, L Gaceta Judicial, 6 de septiembre de 1940.

Colombia, Corte Suprema de Justicia, Sala de Casación Civil, LXXXVIII Gaceta Judicial, 23 de junio de 1958.

Colombia, Corte Suprema de Justicia, Sala de Casación Civil, Expediente 5372, 9 de agosto de 2000.

Colombia, Corte Suprema de Justicia, Sala de Casación Civil, Expediente 6146, 2 de agosto de 2001, magistrado ponente Carlos Ignacio Jaramillo-Jaramillo. Disponible en: http://consultajurisprudencial.ramajudicial.gov.co/WebRelatoria/ csj/index.xhtml

Colombia, Corte Suprema de Justicia, Sala de Casación Civil, Expediente 1997-9124 02, 2 de febrero de 2005.

Colombia, Corte Suprema de Justicia, Sala de Casación Civil, Expediente 1999-0008701, 7 de febrero de 2007.

Colombia, Corte Suprema de Justicia, Sala de Casación Civil, Expediente 254.01, 9 de agosto de 2007.

Colombia, Corte Suprema de Justicia, Sala de Casación Civil, Expediente 1997-0184601, 14 de agosto de 2007.

Colombia, Corte Suprema de Justicia, Sala de Casación Civil, Expediente 258753184 001199400200 01, 16 de agosto de 2007.

Colombia, Corte Suprema de Justicia, Sala de Casación Civil, Expediente 258993193 992199900629 01, 30 de abril de 2009, magistrado ponente Pedro Octavio Munar-Cárdenas.

Colombia, Corte Suprema de Justicia, Sala de Casación Civil, Expediente 05360-31-03001-2003-00164-01, 7 de octubre de 2009.

Colombia, Corte Suprema de Justicia, Sala de Casación Civil, Expediente 11001-3103008-1998-00081-01, 30 de agosto de 2010.

Colombia, Corte Suprema de Justicia, Sala de Casación Civil, Expediente 11001-31-03009-1997-01799-01, 27 de julio de 2015. 
Colombia, Corte Suprema de Justicia, Sala de Casación Civil, Expediente 15001-31-03001-2008-00043-01, 21 de junio de 2016. 